Check for updates

Cite this: RSC Adv., 2018, 8, 29526

\title{
Fabrication of a Cu/Zn co-incorporated calcium phosphate scaffold-derived GDF-5 sustained release system with enhanced angiogenesis and osteogenesis properties $\uparrow$
}

\author{
Dongqin Xiao, (D) $t^{\mathrm{a}}$ Fei Yang, $\$^{\mathrm{a}}$ Qiao Zhao, ${ }^{\mathrm{b}}$ Shixiao Chen, ${ }^{\mathrm{c}}$ Feng Shi, ${ }^{\mathrm{d}}$ \\ Xiaocong Xiang, ${ }^{a}$ Li Deng, ${ }^{a}$ Xiao Sun, ${ }^{a}$ Jie Weng ${ }^{e}$ and Gang Feng ${ }^{* a b}$
}

Synthetic scaffolds with multifunctional properties, including angiogenesis and osteogenesis capacities, play an essential role in accelerating bone regeneration. In this study, various concentrations of $\mathrm{Cu} / \mathrm{Zn}$ ions were incorporated into biphasic calcium phosphate (BCP) scaffolds, and then growth differentiation factor-5 (GDF-5)-loaded poly(lactide-co-glycolide) (PLGA) microspheres were attached onto the iondoped scaffold. The results demonstrated that with increasing concentration of dopants, the scaffold surface gradually changed from smooth grain crystalline to rough microparticles, and further to a nanoflake film. Additionally, the mass ratio of $\beta$-tricalcium phosphate/hydroxyapatite increased with the dopant concentration. Furthermore, GDF-5-loaded PLGA microspheres attached onto the BCP scaffold surface exhibited a sustained release. In vitro co-culture of bone mesenchymal stem cells and vascular endothelial cells showed that the addition of Cu/Zn ions and GDF-5 in the BCP scaffold not only accelerated cell proliferation, but also promoted cell differentiation by enhancing the alkaline phosphatase activity and bone-related gene expression. Moreover, the vascular endothelial growth factor secretion level increased with the dopant concentration, and attained a maximum when GDF-5 was added into the ions-doped scaffold. These findings indicated that BCP scaffold co-doped with $\mathrm{Cu} /$ Zn ions exhibited a combined effect of both metal ions, including angiogenic and osteogenic capacities. Moreover, GDF-5 addition further enhanced both the angiogenic and osteogenic capacities of the BCP scaffold. The Cu/Zn co-incorporated BCP scaffold-derived GDF-5 sustained release system produced multifunctional scaffolds with improved angiogenesis and osteogenesis properties.

Received 25th June 2018 Accepted 15th August 2018

DOI: $10.1039 / c 8 r a 05441 \mathrm{j}$

rsc.li/rsc-advances

\section{Introduction}

Because of the limitations of the current therapies based on the usage of autologous bone grafts, allografts and xenografts, synthetic scaffolds for the repair of segmental bone defects have attracted increasing interest. ${ }^{1,2}$ The ideal synthetic scaffold for

${ }^{a}$ Research Institute of Tissue Engineering and Stem Cells, Nanchong Central Hospital, The Second Clinical College of North Sichuan Medical College, Nanchong, Sichuan, 637000 China. E-mail: fenggangncch@163.com

${ }^{b}$ Department of Orthopedics, Southwest Medical University, Luzhou, Sichuan, 646000 China

${ }^{c}$ Radiology Department, Nanchong Central Hospital, Nanchong, Sichuan, 637000 China

${ }^{d}$ China Collaboration Innovation Center for Tissue Repair Material Engineering Technology, China West Normal University, Nanchong, Sichuan, 637000 China

${ }^{e}$ Key Laboratory of Advanced Technologies of Materials (Ministry of Education), School of Materials Science and Engineering, Southwest Jiaotong University, Chengdu, Sichuan, 610031 China

$\dagger$ Electronic supplementary information (ESI) available. See DOI: 10.1039/c8ra05441j

\$ Authors contributed equally to this work. bone tissue repair should promote cell migration, angiogenesis and new bone formation. ${ }^{3}$ To achieve these requirements, threedimensional scaffolds were tailored by controlling porous structure, surface topography and chemical composition to enhance their osteoinduction properties for better healing effects. ${ }^{4-7}$ However, poor angiogenesis within synthetic scaffolds has been recognized as the main hurdle limiting the clinical application of bone tissue-engineering scaffolds. Implant failure and osteonecrosis occurred when there was a lack of inner vascular network to supply nutrients and oxygen to cells within the tissue. ${ }^{8,9}$ Therefore, numerous efforts have been devoted to stimulate or facilitate angiogenesis or vascularization in bone tissue-engineering scaffolds as well as osteogenesis, including the delivery of vascular endothelial growth factor (VEGF) or bone morphogenetic protein-2 (BMP-2) released from polymer or ceramic scaffolds. ${ }^{10,11}$ Although desirable results have been obtained during BMP-2 and VEGF applications in bone tissue repair, it is noteworthy that serious side effects, including ectopic and unwanted vascularization and bone formation, have become increasingly resistant to 
approving the usage of such proteins. ${ }^{\mathbf{1 2 - 1 4}}$ Therefore, alternative safer growth factors or potential strategies should be explored to enhance the osteogenesis and angiogenesis capacities of bone tissue-engineering scaffolds.

Growth differentiation factor-5 (GDF-5), as a member of the BMP family, is best known for its role in early limb development and long-bone fracture healing. However, GDF-5 has been studied less in bone tissue regeneration compared with BMP-2, which may be associated with its origin from cartilage tissue. Previous studies have found that GDF-5 promoted the recruitment of mesenchymal stem cells (MSCs) and their differentiation into chondrocytes, thus accelerating chondrogenesis and joint formation. ${ }^{15,16}$ In recent years, GDF-5 has shown great application potential in bone tissue repair. GDF-5 deficiency resulted in delayed bone healing, ${ }^{17}$ whereas its addition promoted MSCs osteogenic differentiation and VEGF expression. ${ }^{18,19}$ More importantly, implants loaded with GDF-5 displayed no evidence of peri-implant bone remodeling or seroma formation in vivo, ${ }^{20}$ indicating a potentially safer substitute for BMP-2. Therefore, GDF-5 is a potential candidate for bone tissue regeneration by enhancing osteogenesis and angiogenesis.

Calcium phosphate scaffolds have been widely used for bone regeneration due to their similarity to the inorganic component of human bones and excellent biocompatibility. In particular, biphasic calcium phosphate (BCP) composed of hydroxyapatite (HA) and $\beta$-tricalcium phosphate $(\beta$-TCP) has attracted increasing interest, because of its bioactivity and degradability. Recently, the addition of trace element (e.g. Si, $\mathrm{Mg}$, Co, etc.) into calcium phosphate scaffolds has been reported to achieve multifunctional ceramics to meet increasingly complex clinical demands. ${ }^{21-23}$ These trace elements have been found to play an important role in modifying physicochemical properties and biological response of tissue-engineering scaffolds. Especially, $\mathrm{Zn}$ is regarded as an essential trace element in human skeletal development and exhibits an inhibitory effect on HA growth through decreasing lattice parameters and thermal stability. ${ }^{24}$ Also, the incorporation of $\mathrm{Zn}^{2+}$ into various calcium phosphates has shown increased osteogenic differentiation of MSCs in vitro as well as new bone formation in vivo. ${ }^{25,26} \mathrm{In}$ addition, $\mathrm{Cu}$ as a co-factor of many enzymes has been shown to stimulate endothelial cells migration and VEGF expression, and further enhance angiogenesis in vivo. ${ }^{27,28}$ Enhanced angiogenesis potential and antibacterial properties were observed when $\mathrm{Cu}^{2+}$ was doped into mesoporous bioactive glass. ${ }^{29}$ These results indicated that calcium phosphate scaffolds incorporating $\mathrm{Cu}$ / $\mathrm{Zn}$ ions have interesting multifunctional properties that need further investigation for bone tissue engineering.

The above findings showed that synthetic scaffolds with multifunctional properties, including angiogenesis and osteogenesis capacities, could be developed by preparing $\mathrm{Cu} / \mathrm{Zn}$ coincorporated calcium phosphate scaffolds-derived GDF-5 sustained release system. To the best of our knowledge, there are no previous studies investigating the incorporation of metallic ions and GDF-5 into calcium phosphate scaffold for bone regeneration. Therefore, this study aimed both to prepare $\mathrm{Cu}$ / Zn co-incorporated calcium phosphate scaffolds with GDF-5 sustained release system and to investigate the combined effect of the metallic ions and GDF-5 on the scaffold cytocompatibility. In particular, the effects of $\mathrm{Cu} / \mathrm{Zn}$ coincorporation on the physicochemical properties of calcium phosphate, the osteogenic differentiation and VEGF expression of cells were evaluated.

\section{Experimental}

\section{Preparation of BCP scaffolds doped with $\mathrm{Cu} / \mathrm{Zn}$ ions}

Firstly, calcium deficient apatite powders co-doped with $\mathrm{Cu} / \mathrm{Zn}$ ions were synthesized by a wet chemical precipitation method. ${ }^{30}$ Briefly, a mixed solution of $\mathrm{Ca}\left(\mathrm{NO}_{3}\right)_{2} \cdot 4 \mathrm{H}_{2} \mathrm{O}, \mathrm{Zn}\left(\mathrm{NO}_{3}\right)_{2} \cdot 6 \mathrm{H}_{2} \mathrm{O}$, $\mathrm{Cu}\left(\mathrm{NO}_{3}\right)_{2} \cdot 3 \mathrm{H}_{2} \mathrm{O}$ and sodium dodecyl sulfate $(0.03 \mathrm{M})$ were prepared and added dropwise into $\left(\mathrm{NH}_{4}\right)_{2} \mathrm{HPO}_{4}$ solution under stirring at room temperature with $\mathrm{a}(\mathrm{Ca}+\mathrm{Zn}+\mathrm{Cu}) / \mathrm{P}$ molar ratio of 1.55 . The $\mathrm{pH}$ of the solution was adjusted to 8 by adding ammonia solution. The reaction solution were further stirred for $4 \mathrm{~h}$ and aged for $24 \mathrm{~h}$. The reaction precipitate was removed, rinsed with water and lyophilized. Different amounts of $\mathrm{Ca}^{2+}$, $\mathrm{Zn}^{2+}$ and $\mathrm{Cu}^{2+}$ were added (Table 1 ). The porous scaffolds were fabricated using alginate hydrogel beads as porogen (see ref. 31 for detailed procedures) and then sintered at $1200{ }^{\circ} \mathrm{C}$ for $2 \mathrm{~h}$ to form ceramics. The corresponding scaffold products were named depending on increasing $\mathrm{Cu} / \mathrm{Zn}$ content as P0, P1, P2 and $\mathrm{P} 3$, respectively.

\section{In vitro release of ions from prepared scaffolds and ion extraction preparation}

The release kinetics of ions from the porous scaffolds (P0, P1 and P2) were determined by immersing them in $3 \mathrm{ml}$ buffer solution (50 mM Tris-NaCl buffer, $\mathrm{pH}=7.4$ or $50 \mathrm{mM}$ sodium acetate buffer, $\mathrm{pH}=5.8$ ) and placed in a shaking water bath $\left(37{ }^{\circ} \mathrm{C}, 80 \mathrm{rpm}\right)$. At predetermined intervals, the supernatant was collected and stored at $4{ }^{\circ} \mathrm{C}$, and the fluid was replenished. The collections were analyzed by inductively coupled plasma mass spectrometer (ICP-MS).

The ion extraction of scaffold P2 was prepared according to the International Organization for Standardization method (ISO 10993-12). Briefly, the scaffold was immersed into Dulbecco's modified eagle's medium (DMEM) at a mass/volume ratio of $0.1 \mathrm{~g} \mathrm{ml}^{-1}$ at $37{ }^{\circ} \mathrm{C}$ for $24 \mathrm{~h}$. The supernatant was collected, filter-sterilized and stored at $4{ }^{\circ} \mathrm{C}$ for further use. In parallel, culture medium with appropriate concentration of $\mathrm{Zn}^{2+}\left(1 \mu \mathrm{g} \mathrm{ml} \mathrm{m}^{-1}\right)$ or $\mathrm{Cu}^{2+}\left(0.7 \mu \mathrm{g} \mathrm{ml}^{-1}\right)$ according to the ions release profiles were prepared as the control medium.

Table 1 Samples prepared using different concentrations of reaction reagents and the mass fraction ratio of $\beta-T C P / H A$ calculated from $X-$ ray diffraction spectrum

\begin{tabular}{lllll}
\hline Scaffold products & $\mathrm{Ca}(\mathrm{M})$ & $\mathrm{Cu}(\mathrm{M})$ & $\mathrm{Zn}(\mathrm{M})$ & Ratio $(\beta-\mathrm{TCP} / \mathrm{HA})$ \\
\hline P0 & 0.85 & - & - & $59 / 41$ \\
P1 & 0.84 & 0.005 & 0.005 & $64 / 36$ \\
P2 & 0.81 & 0.02 & 0.02 & $70 / 30$ \\
P3 & 0.75 & 0.05 & 0.05 & -
\end{tabular}




\section{Attachment of GDF-5-loaded microspheres onto ions-doped BCP scaffolds}

First, GDF-5-loaded microspheres were prepared using the water-in-oil-in-water technique with polyvinyl alcohol (PVA) as the emulsifier. ${ }^{32}$ Briefly, $10 \mathrm{mg}$ PLGA $\left(M_{\mathrm{w}}: 20000\right.$, lactide: glycolide $=75: 25$; Daigang Biotech, China) was dissolved in $1 \mathrm{ml}$ dichloromethane (DCM) as the oil phase. GDF-5 was dissolved in deionized water and emulsified in the oil phase to form emulsion. This emulsion was added dropwise into $100 \mathrm{ml}$ water containing $1 \mathrm{~g}$ PVA and homogenized on an ice water bath (1000 rpm, $5 \mathrm{~min}$ ). After removal from the bath, the emulsion was stirred at $300 \mathrm{rpm}$ for $4 \mathrm{~h}$ to allow DCM to evaporate. The formed microspheres were then collected by centrifugation, rinsed with deionized water and lyophilized.

Second, the obtained microspheres were attached onto porous scaffold (P2) by vacuum (10 Pa) drying. Briefly, $5 \mathrm{mg}$ microspheres were dispersed in $1 \mathrm{ml}$ water and the suspension was pipetted onto the scaffold. The scaffold was placed in an evacuated desiccator for $2 \mathrm{~h}$ and stored at $-20{ }^{\circ} \mathrm{C}$ for further use. The GDF-5-loaded scaffold was termed P2/GDF-5.

\section{In vitro release of GDF-5 from scaffolds}

Three scaffolds loaded with GDF-5 microspheres (P2/GDF-5) were each immersed in $2 \mathrm{ml}$ phosphate-buffered saline (PBS) and placed in shaking bath $\left(37^{\circ} \mathrm{C}, 100 \mathrm{rpm}\right)$ for 30 days. At predetermined times, $1 \mathrm{ml}$ supernatant was collected and quantified using enzyme-linked immunosorbent assay (ELISA) kit (Cusabio Biotech, Co. Ltd., China) according to the manufacturer's instructions. Then, fluid media was replenished after each removal.

\section{Characterization of the prepared scaffolds}

The morphology and composition of the samples were analyzed by scanning electron microscopy (SEM, JEOL JSM7001F) equipped with an energy dispersive X-ray (EDX) spectrometer. The phase structures were analyzed by X-ray diffraction (XRD, X'PertPro MPD, CuK $\alpha, 35 \mathrm{~mA}, 45 \mathrm{kV}$ ) and Fourier transform infrared spectroscopy (FTIR, Nicolet 5700). The amount of ions released from scaffolds was analyzed by ICP-MS (NexION 350X, Perkin Elmer). The specific surface area was analyzed by nitrogen adsorption method (Gemini VII 2390, Micrometrics). The surface chemical composition was investigated using X-ray photoelectron spectrometer (XPS, XSAM800, Kratos) equipped with $\mathrm{Mg} \mathrm{K} \alpha$ radiation $(12 \mathrm{kV}$ and $12 \mathrm{~mA})$.

\section{In vitro cellular biocompatibility}

To simulate the real environment of tissue repair process in vivo, the prepared scaffolds were evaluated using the co-culture system of bone mesenchymal stem cells (BMSCs) and vascular endothelial cells (VECs). BMSCs and VECs were purchased from Typical Culture Preservation Commission Cell Bank, Chinese Academy of Sciences (Shanghai, China), and cultured according to previous research reports. ${ }^{3,34}$ After 3-5 passages, BMSCs and VECs were mixed at a $1: 1$ ratio in a $1: 1$ mixture of endothelial basal medium and DMEM. ${ }^{35}$ The cells with a density of $1 \times 10^{5}$ per scaffold were seeded and co-cultured into the scaffolds.

To investigate cell morphologies on scaffolds, after culturing for 5 days, the scaffolds were removed and fixed in $2.5 \%$ glutaraldehyde solution for $1 \mathrm{~h}$, followed by dehydration in a graded ethanol series (70, 80, 90 and 100\%). Then, the samples were coated with gold and observed by SEM. In addition, the cells seeded on the scaffolds were fixed in $4 \%$ paraformaldehyde solution for $5 \mathrm{~min}$, followed by incubation in PBS containing 2-(4-amidinophenyl)-6-indolecarbamidine dihydrochloride (DAPI, $100 \mathrm{ng} \mathrm{ml}{ }^{-1}$ ) for $5 \mathrm{~min}$. Following thorough rinsing in PBS, the cells on scaffolds were observed using a fluorescence microscope (DMIL, Leica, Germany). The images were processed and quantified using Image Pro Plus software (IPP, Media Cybernetics, USA).

After 1, 4 and 7 days of culture, the cell proliferation activity was determined by Cell Counting Kit-8 (CCK-8, Dojindo, Japan) assay according to the manufacturer's instructions. The cell alkaline phosphatase (ALP) activity was quantitatively determined after 7 and 14 days of culture using an ALP microplate test kit (QuantiChrom ${ }^{\mathrm{TM}}$ alkaline phosphatase assay kit, Bioassay Systems, CA, USA) according to the manufacturer's instructions. ${ }^{5}$

To evaluate the gene expressions of ALP, osteopontin (OPN), osteocalcin (OCN) and osterix (OSX), polymerase chain reaction (PCR)-based technology was applied according to our previous report. ${ }^{36}$ Total cell RNA was extracted from the co-cultured cells at day 14 using TRIzol reagent (Invitrogen, USA) as specified by the manufacturer. All experiments were performed in triplicate for yield validation. The relative expression levels of genes were examined using the Gene Genius program by normalizing with glyceraldehyde-3-phosphate-dehydrogenase (GAPDH) gene as an endogenous control.

Moreover, the effects of the prepared scaffolds on VEGF expression were investigated by ELISA analysis. Briefly, after coculture of BMSCs and VECs $\left(1 \times 10^{5}\right.$ cells per $\left.\mathrm{ml}\right)$ in the prepared scaffolds for 14 days, the supernatants were collected and quantified using ELISA kits (R\&D Systems, Inc., Minneapolis, MN, USA) according to the manufacturer's instructions.

\section{Statistical analysis}

The statistical analysis was performed by SPSS software (SPSS Inc., Chicago, IL, USA) using non-parametric Kruskal-Wallis test. All the data were expressed as means \pm standard deviation (SD). A $p$-value $<0.05$ was considered to be statistically significant.

\section{Results}

\section{Characterization of the prepared scaffolds}

SEM analysis showed that all the types of scaffolds had interconnected porous structures with a similar macropore size ranging from 200-600 $\mu \mathrm{m}$ (Fig. 1A). High magnification images (Fig. 1B) showed that the surface of the scaffold P0 was composed of smooth crystalline grains (size: $\sim 1 \mu \mathrm{m}$ ) when no dopant was added. When the adding dopant concentration was 


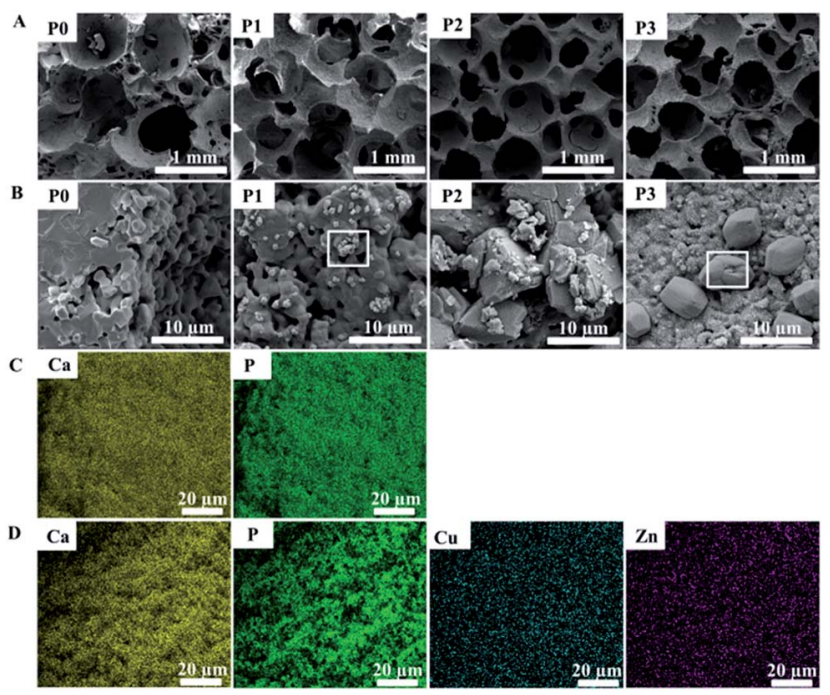

Fig. 1 SEM images showing the microstructure and morphology of various scaffolds: $(A) \times 100$, (B) $\times 10 \mathrm{~K}$; the elements distribution on the surface of (C) the scaffold P0 and (D) scaffold P2.

$0.005 \mathrm{M}$, cubical nanoparticles (size: $\sim 200 \mathrm{~nm}$, shown in the white square) appeared on the smooth grains of the scaffold P1. When the adding dopant concentration was further increased to $0.02 \mathrm{M}$, the scaffold P2 surface turned to rough microparticles (size: $0.5-10 \mu \mathrm{m}$ ). Further increase of the adding dopant concentration to $0.05 \mathrm{M}$ resulted in the formation of prism particles (size: $\sim 8 \mu \mathrm{m}$, shown in the white square) growing on the nanoflakes film of the scaffold P3. EDS analysis indicated that a small amount of $\mathrm{Cu}$ and $\mathrm{Zn}$ were uniformly dispersed on the surface of the scaffold P2 (Fig. 1D), whereas only Ca and P (P2) were observed for the scaffold P0 (Fig. 1C). In addition, the specific surface area of the scaffolds prepared at different dopant concentrations $(0,0.005,0.02$ and $0.05 \mathrm{M})$ were 0.57, $0.81,0.99$ and $0.38 \mathrm{~m}^{2} \mathrm{~g}^{-1}$, respectively.

The crystal phases of all samples determined by XRD were shown in Fig. 2a. When the adding dopant concentrations were $<0.05 \mathrm{M}$, the XRD spectra of the samples (P0, P1 and P2) showed similar patterns, except for the difference in the relative intensities of HA/ $\beta$-TCP phase. With the progressive increase of adding dopant, the peak of $\left(\begin{array}{lll}2 & 1 & 1\end{array}\right)$ at $31.8^{\circ}$ attributed to HA decreased in relative intensity. When the adding dopant concentration was $0.05 \mathrm{M}$, the sample P3 showed peaks of $\beta$ -
TCP, but almost no HA peaks were observed. The mass fraction ratio of $\beta$-TCP/HA in the samples was calculated using the ratio of $I_{\mathrm{TCP}} / I_{\mathrm{HA}}$, where $I_{\mathrm{TCP}}$ and $I_{\mathrm{HA}}$ represent the normalized integrated intensity of $\beta$-TCP ( $\left.\begin{array}{lll}0 & 2 & 10\end{array}\right)$ peak at $31.1^{\circ}$ and HA ( $\left.\begin{array}{lll}2 & 1 & 1\end{array}\right)$ peak, respectively. ${ }^{37}$ The ratio values were shown in the Table 1. With the increase of adding dopant concentration, the mass fraction of $\beta$-TCP increased, whereas that of HA decreased. When the dopant concentration was $0.05 \mathrm{M}$, the product consisted of pure $\beta$-TCP phase.

The FTIR spectra (Fig. 2b) of the samples showed the characteristic peaks of calcium phosphate. When the adding dopant concentrations were $<0.05 \mathrm{M}$, for the samples (P0, P1 and P2), the peaks at 571, 603, 1045 and $1091 \mathrm{~cm}^{-1}$ were attributed to phosphate bands in $\mathrm{HA},{ }^{38}$ while the peaks at 551, 603, 942, 970, 1015 and $1122 \mathrm{~cm}^{-1}$ were attributed to the band shoulders of $\beta$ TCP. ${ }^{39}$ When the adding dopant concentrations were $0.05 \mathrm{M}$, the splitting peaks of sample $\mathrm{P} 3$ at $571 \mathrm{~cm}^{-1}$ disappeared, indicating the formation of pure $\beta$-TCP.

Elemental analysis of the products was performed using an XPS (Fig. 2c). The main peaks observed for the samples (P0, P1 and P2) contained Ca2p (346.9 eV), P2p (132.9 eV), P2s (190.5 $\mathrm{eV})$, O1s (530.8 eV) and C1s (284.6 eV). For the samples P1 and $\mathrm{P} 2$, almost no $\mathrm{Cu}$ or $\mathrm{Zn}$ peaks were observed. Whereas, in addition to the main peaks for Ca2p (347.1 eV), P2p (133.1 eV), P2s (190.5 eV), O1s (531.1 eV) and C1s (284.6 eV), additional $\mathrm{Cu} 2 \mathrm{p}(933.9 \mathrm{eV})$ and $\mathrm{Zn} 2 \mathrm{p}(1022.3 \mathrm{eV})$ peaks were both detected for the sample P3.

\section{The release kinetics of metallic ions from the prepared scaffolds}

The ion concentration measurements in neutral buffer showed that both $\mathrm{Cu}$ and $\mathrm{Zn}$ exhibited a sustained and controlled release profile from the samples P1 and P2 over a time duration of one month (Fig. 3a and b). The cumulative release of $\mathrm{Cu}$ and Zn from sample P2 showed a significantly higher tendency than that from sample P1. In addition, the sustained release profile of Ca was detected from all the samples (P0, P1 and P2), with $\mathrm{Ca}$ cumulative release from samples $\mathrm{P} 1$ and $\mathrm{P} 2$ significantly faster than that from sample P0 (Fig. 3c). Moreover, the cumulative release of $\mathrm{Cu}, \mathrm{Zn}$ and $\mathrm{Ca}$ from sample $\mathrm{P} 2$ in acidic buffer was significantly higher in comparison with that in neutral buffer (ESI Fig. S1 $\dagger$ ). The cumulative release of $\mathrm{Cu}$ and $\mathrm{Zn}$ at $\mathrm{pH}=5.8$ reached approximately $32 \%$ after 30 days, while only
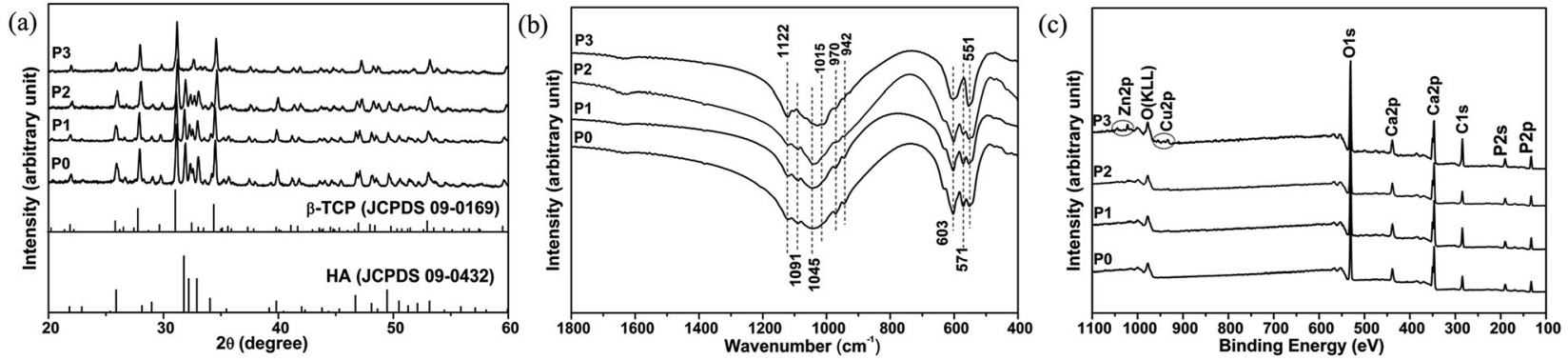

Fig. 2 (a) XRD patterns, (b) FTIR spectra and (c) XPS spectra of various scaffolds. 

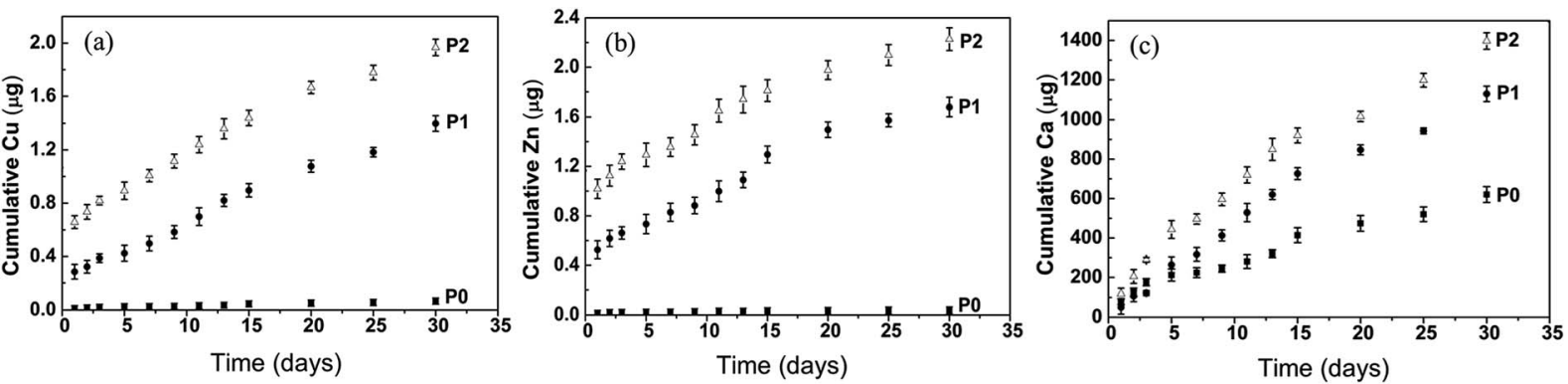

Fig. 3 Metallic ions release from various scaffolds in Tris-NaCl buffer: (a) $\mathrm{Cu}$, (b) $\mathrm{Zn}$ and (c) Ca ions release from scaffolds P0, P1 and P2.

approximately $19 \%$ at $\mathrm{pH}=7.4$ (ESI Fig. S1a and $\mathrm{b}_{\dagger}^{\dagger}$ ). Additionally, the cumulative $\mathrm{Ca}$ release at $\mathrm{pH}=5.8$ reached approximately $15 \%$ after 30 days, while only approximately $2 \%$ at $\mathrm{pH}=7.4$ (ESI Fig. S1c $\dagger$ ).

The morphology of GDF-5-loaded microspheres and GDF-5 release kinetics from the $\mathrm{BCP}$ scaffolds

The GDF-5-loaded microspheres were spherical in shape and 3$20 \mu \mathrm{m}$ in diameter (Fig. 4a). Also, some residual emulsifier was observed on microsphere surface (Fig. 4a1). After dispensing as a suspension in scaffolds by vacuum drying, the microspheres were well-dispersed and immobilized onto the scaffold surface (Fig. 4b and b1). The profiles of GDF-5 release from the scaffold showed an initial burst release $(\sim 34 \%)$ during the first 2 days, followed by a relative slower release during the next 8 days, and thereafter by a steady release up to 30 days (Fig. 4c). The cumulative release reached approximately $74 \%$ after 30 days.
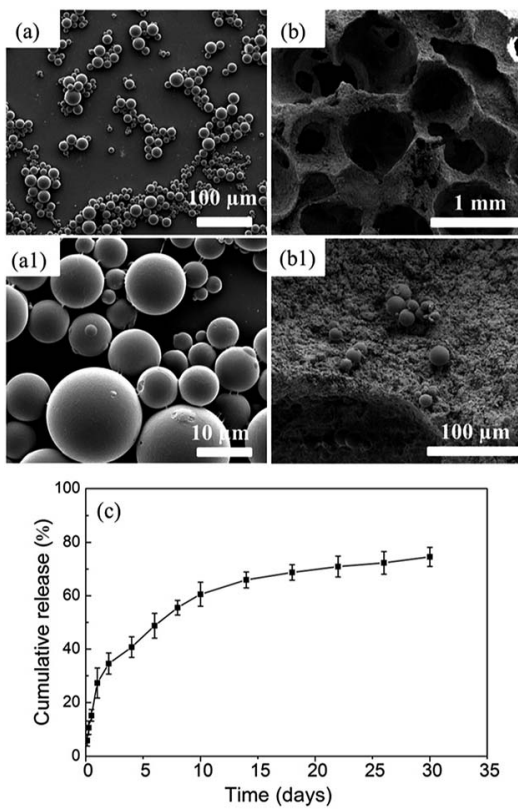

Fig. 4 SEM images of PLGA microspheres loaded with GDF-5: (a) $\times 500$, (a1) $\times 5$ K; SEM images of the scaffold P2 loaded with PLGA microspheres: (b) $\times 100$, (b1) $\times 1 \mathrm{~K}$; (c) the cumulative release profile of GDF-5 from the scaffold P2.

\section{In vitro cell response of the prepared scaffolds}

To evaluate the growth behavior of BMSCs and VECs on the prepared scaffolds, after co-culture for 5 days, the cell attachment and morphology on the scaffolds were observed by SEM and fluorescent staining (Fig. 5). The fluorescent images showed that cells were distributed along the pore wall of the scaffolds and the statistical analysis (not shown) found that cell densities on the ions-doped BCP scaffolds (P1 and P2) were significantly greater than that on pure scaffold (P0) (Fig. 5A). Comparatively, the highest cell density was observed on the ions-doped scaffolds loaded with GDF-5 microspheres. SEM images showed that cells on these scaffolds exhibited a wellspread morphology and cell density distributions on the various scaffolds were consistent with the fluorescent results (Fig. 5B). Notably, compared with cell adhesion on the surface of the scaffold P2, cells on the scaffold P2/GDF-5 fused and formed capillary-like structures.

In addition, cell proliferation was quantitatively determined using CCK-8 method, as shown in Fig. 6a. Cells proliferation on all types of scaffolds increased with the culture time. On day 1 , there were no significant differences between the four groups. On days 4 and 7 , cell proliferations on scaffolds $\mathrm{P} 2$ and P2/GDF-5 were significantly greater than on scaffolds P0 and P1. Furthermore, cell proliferation had an increase tendency on the scaffold P2/GDF-5 compared with the scaffold P2, but no significant difference was observed. Additionally, the ALP activity of cells was measured and shown in Fig. 6b. The ALP activity of cells on all types of scaffolds continually increased over 14 days. On days 7 and 14, the ALP activities of cells on scaffolds $\mathrm{P} 2$ and P2/GDF-5 were

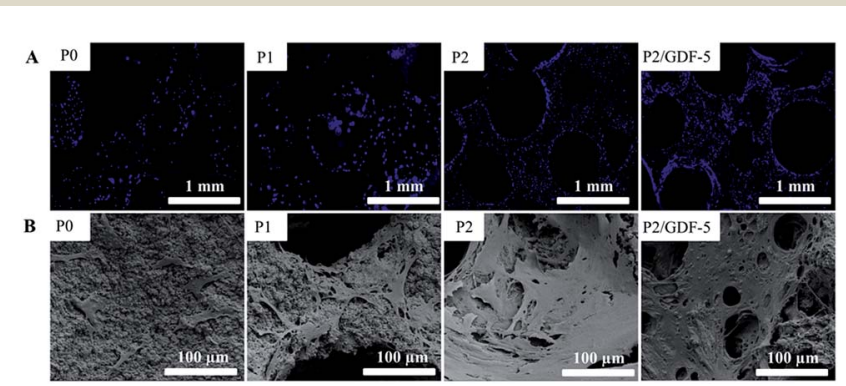

Fig. 5 (A) Fluorescence images of cells cultured on various scaffolds and (B) SEM images of cell attachment on various scaffolds. 

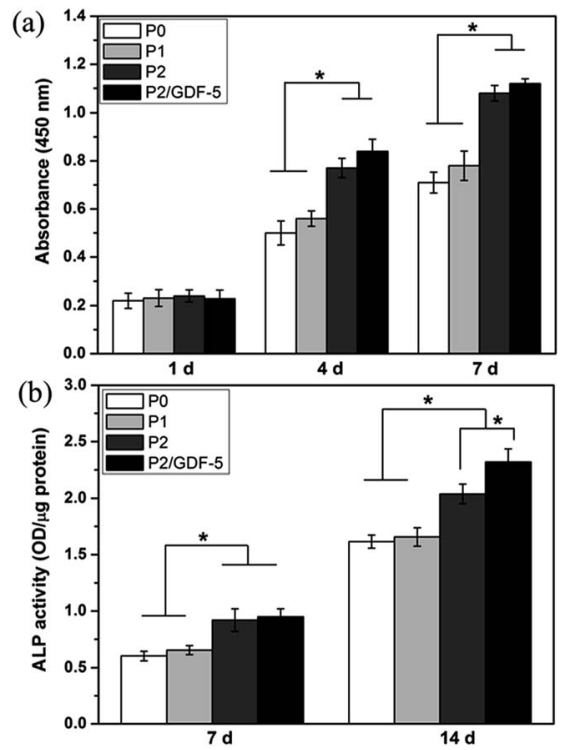

Fig. 6 (a) The proliferation and (b) ALP activity of cells cultured on various scaffolds. * indicates significant difference between the groups $(p<0.05)$.

significantly greater than those on scaffolds P0 and P1. Furthermore, on day 14, cells cultured on the scaffold P2/GDF5 had a significantly greater ALP activity compared with those on the scaffold $\mathrm{P} 2$.

We also investigated the effects of various scaffolds on the expressions of cell bone-related genes. RT-qPCR analysis (Fig. 7) showed that on day 14, ALP, OCN and OSX expressions of cells on ions-doped scaffolds (P1 and P2) were significantly greater than on the pure scaffold (P0) (Fig. 7a, c and d), whereas there was a slight increasing trend for OPN expression between the groups (Fig. 7b). Furthermore, ALP and OSX expressions of cells on the scaffold P2 were significantly greater than on the scaffold P1. In addition, ALP, OPN and OCN expressions of cells on scaffold P2/ GDF-5 were significantly greater than on the scaffold P2, whereas no significant difference was observed for OSX expression.
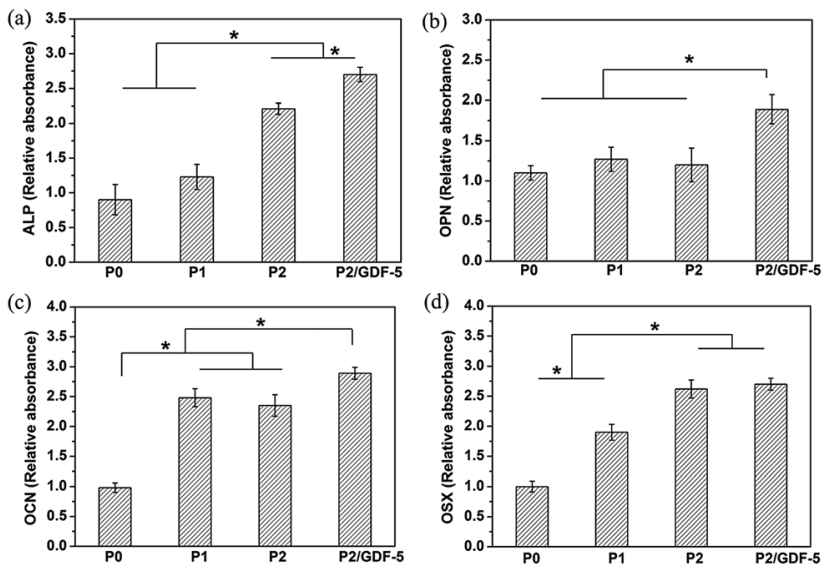

Fig. 7 Bone-related gene expression, including (a) ALP, (b) OPN, (c) OCN and (d) OSX, of cells cultured on various scaffolds for 14 days. * indicates significant difference between the groups $(p<0.05)$.

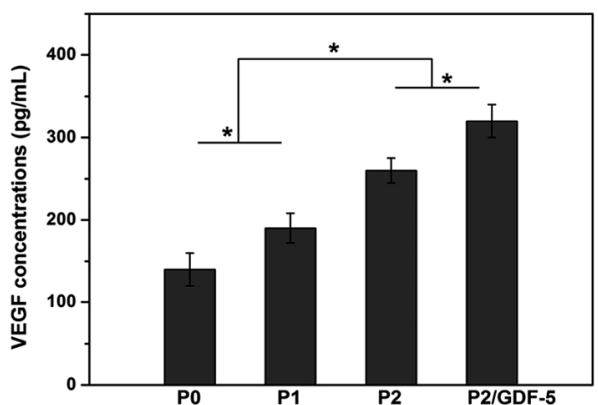

Fig. 8 VEGF secretion by cells cultured on various scaffolds for 14 days. * indicates significant difference between the groups $(p<0.05)$.

In addition, ELISA analysis (Fig. 8) showed that the ionsdoped scaffolds (P1 and P2) significantly improved VEGF secretion compared with the pure scaffold (P0). The VEGF secretion amount increased with the adding dopant concentration. Moreover, VEGF secretion of cells on the scaffold P2/ GDF-5 was significantly higher than that on the scaffold P2.

\section{Discussion}

In spite of substantial advances in bone tissue engineering, vascularization remains a major challenge that restricts the clinical application of large bone grafts. Synthetic scaffolds capable of accelerating osteogenesis and angiogenesis are regarded as an effective solution. ${ }^{40}$ The main objective of this study was the incorporation of $\mathrm{Cu} / \mathrm{Zn}$ ions into BCP scaffolds capable of GDF-5 sustained delivery to obtain novel multifunctional scaffolds for bone regeneration. The prepared BCP scaffolds had macropores ranging from 200-600 $\mu \mathrm{m}$ and showed good interconnectivity, which met the requirements for vascular and cell/bone ingrowth. ${ }^{41}$ In addition to an appropriate pore structure, $\mathrm{Cu}^{2+}$ and $\mathrm{Zn}^{2+}$ were co-doped into BCP scaffolds with the expectation of enhancing angiogenesis and osteogenesis simultaneously. When no dopant was added, the scaffold surface was smooth, similarly to a previous study on the pure BCP ceramic surface. ${ }^{42}$ In comparison, with an increase in adding dopant concentration, the scaffold surface tended to change from smooth grain crystalline (P0), to nanoparticles growing onto the smooth grain (P1), to rough microparticles (P2) and further to nanoflakes film (P3). Huang et $a l^{43}$ found that the co-substitution of $\mathrm{Cu} / \mathrm{Zn}$ ions in HA coating on pure $\mathrm{Ti}$ resulted in HA morphology variation from needle to flaky. Previous studies indicated that the metallic ions could nonuniformly incorporate into the crystal surface and further change crystal morphology. ${ }^{44,45}$ In addition, the radii of $\mathrm{Cu}^{2+}$ and $\mathrm{Zn}^{2+}$ are both smaller than that of $\mathrm{Ca}^{2+}$, which easily coordinate at $\mathrm{Ca}$ sites in the crystal structure. Therefore, we speculated that these morphological variations might be due to the effects of ion substitutions on the structure and growth of calcium phosphate crystals. Moreover, combining the results of XRD, FTIR and XPS (Fig. 2), it was concluded that with the increase of adding dopant concentration, the mass fraction of $\beta$ TCP increased while that of HA decreased. When the dopant 
concentration was $0.05 \mathrm{M}$, the product consisted of pure $\beta$-TCP phase. This indicated that adding dopants reduced the thermal stability of calcium phosphate at high temperature and resulted in the decomposition of HA to $\beta$-TCP. Because ion release behavior correlated with its biofunction in vivo, BCP scaffolds were immersed into buffer solution to investigate the release kinetics of metallic ions. As Tris- $\mathrm{NaCl}$ and sodium acetate buffer solutions do not contain calcium or phosphate ions, therefore ion dissolution was favored over re-precipitation. The ion concentration measurements indicated that the increase of the $\beta$-TCP mass fraction led to the accelerating degradation of the BCP scaffold, thus facilitating the release of $\mathrm{Cu} / \mathrm{Zn}$ ions. Moreover, $\mathrm{pH}$ decrease accelerated BCP degradation and metallic ions release. Therefore, the incorporation of $\mathrm{Cu} / \mathrm{Zn}$ into the calcium phosphate scaffold was beneficial to sustained release of $\mathrm{Cu} / \mathrm{Zn}$ ions. Subsequently, the microspheres were attached onto the scaffold surface by a vacuum-drying method. This simple room-temperature attachment method was also used to load PLGA microspheres onto Ti porous surface in our previous report. ${ }^{32}$ According to the investigation on the attachment stability and mechanism, ${ }^{32}$ it was concluded that the residual adhesive on the microsphere surface played a key role in the attachment of microspheres onto the scaffold. Also, the sustained release of GDF-5 further showed that the $\mathrm{Cu} / \mathrm{Zn}$ coincorporated BCP scaffold-derived GDF-5 release system was successfully fabricated.

Since angiogenic and osteogenic processes are triggered via the interaction between endothelial cells and bone-forming cells, ${ }^{\mathbf{4 6}}$ the cytocompatibility of the scaffolds was evaluated by direct co-culturing with BMSCs and VECs in accordance with the report by Kang et $a .^{35}$ Cell attachment is a key process affecting their proliferation and following function to form new tissue. The cell morphological observations (Fig. 5) found that the co-cultured cells distributed well and displayed flattened morphology on the walls of the pores, indicating the good cytocompatibility of these scaffolds. Notably, cells on the scaffold P2/GDF-5 formed capillary-like structures, confirming the good angiogenesis-inducing capacity of the scaffold P2/GDF-5. Combing the results of fluorescent image analysis and CCK-8 measurement, it was concluded that the addition of $\mathrm{Cu} / \mathrm{Zn}$ ions and GDF-5 favored the cells proliferation. Several studies have proven that $\mathrm{Cu}^{2+}$ can promote endothelial cells proliferation, ${ }^{\mathbf{2 8 , 4 6}}$ while $\mathrm{Zn}^{2+}$ can promote MSCs proliferation. ${ }^{\mathbf{4 7}}$ Moreover, GDF- 5 was found to enhance MSCs proliferation in a doseand time-dependent manner. ${ }^{48}$ Therefore, the combination of $\mathrm{Cu} / \mathrm{Zn}$ ions and GDF-5 probably played a synergistic role in cell proliferation when co-culture of BMSCs and VECs was performed. Noteworthily, the variation of physical structure of the scaffold surface might affect the cell attachment and proliferation according to previous studies. ${ }^{49,50}$

One of the objectives of adding $\mathrm{Cu} / \mathrm{Zn}$ ions and GDF-5 into BCP scaffolds was to enhance its osteogenesis capacity. ALP activity is regarded as a factor for the early stage of differentiation to mature osteoblasts, and bone forming-related genes including ALP, OPN, OCN and OSX are biochemical markers for osteogenic differentiation. In this study, on day 14, the ALP activity and the expressions of bone forming-related genes (ALP,
OPN and OCN) of cells on scaffold P2/GDF-5 were both significantly greater than those on scaffold P2, while ALP activity and the gene expressions of ALP and OSX of cells on scaffold P2 were significantly greater than those on scaffolds P0 and P1 (Fig. 6 and 7). Therefore, it was speculated that the additions of GDF-5 and appropriate concentrations of $\mathrm{Cu} / \mathrm{Zn}$ ions played an important role in enhancing ALP activity and osteogenic gene expressions. GDF-5 was proved to stimulate osteogenic differentiation by enhancing both ALP activity and mineral formation in vitro. ${ }^{18,51}$ Also, relative study showed that the gene expressions of Runx 2 and OCN were enhanced by GDF- 5 addition in a dosedependent manner. ${ }^{52}$ Our results are in accordance with these studies, indicating that GDF-5 may have a positive role in osteogenesis. Moreover, with the dopant concentration increasing, the increase of mass fraction of $\beta$-TCP indicated that the scaffold became more soluble and favored $\mathrm{Cu} / \mathrm{Zn}$ ions release. Previous studies have shown that $\mathrm{Zn}^{2+}$ at appropriate concentrations does stimulate the osteogenic differentiation of BMSCs, whereas $\mathrm{Cu}^{2+}$ may not play any role in osteogenic differentiation..$^{53,54}$ To confirm these findings, the extraction medium of the scaffold P2 was co-cultured with BMSCs. After 21 days of co-culture of BMSCs and extraction medium, calcium deposition was stained with 1\% Alizarin Red S (Sigma-Aldrich, USA). The preliminary results (ESI Fig. S2 $\dagger$ ) showed that the amounts of mineral formation in the extraction medium as well as $\mathrm{Zn}^{2+}$-added culture medium were significantly greater than those in the blank culture medium or $\mathrm{Cu}^{2+}$-added culture medium. The results indicated that $\mathrm{Zn}^{2+}$ played a positive role in osteogenesis when released from the scaffold. Also, this is in agreement with the evidence found in the literature showing that $\mathrm{Zn}^{2+}$ has a greater osteogenic capacity than $\mathrm{Cu}^{2+} .{ }^{55}$ Based on the above analysis, we concluded that GDF- 5 and $\mathrm{Zn}^{2+}$ played a combined effect on enhancing the osteogenesis capacity of BCP scaffold.

Another objective of this study was to enhance the angiogenesis capacity of the scaffold. It is well known that angiogenesis is mediated by the coordinated action of various growth factors, especially VEGF is regarded as an important angiogenic stimulator. ${ }^{56}$ VEGF can promote endothelial cells migration and proliferation, and the formation of tubular structures or vessels, finally accelerating tissue repair. In this study, the VEGF secretion level increased with the adding dopant concentration and reached a maximum when GDF-5 was added (Fig. 8), suggesting the angiogenic potential of $\mathrm{Cu} / \mathrm{Zn}$ ions and GDF-5. Zeng et al. ${ }^{57}$ found that GDF-5 promoted the angiogenesis of MSCs by up-regulation of VEGF expression. Moreover, GDF-5 addition was proved to significantly enhance blood vessel formation compared with BMP-2 in vivo. ${ }^{58}$ Our finding of enhanced VEGF expression was consistent with these results. In this study, PLGA microspheres were successfully attached onto the scaffold surface and exhibited a sustained GDF-5 release (Fig. 4). The controlled release of GDF- 5 with better retention significantly prolonged the osteogenesis and angiogenesis capacities of the BCP scaffold. In addition, studies have proved that an appropriate concentration of $\mathrm{Cu}^{2+}$ can stimulate the angiogenesis of VECs via stimulating VEGF secretion and up-regulating 
downstream signalling events. ${ }^{59}$ To evaluate the angiogenesis capacity of the ions released from the scaffold, the extraction medium of the scaffold P2 was co-cultured with VECs. VECs were seeded onto Matrigel (Sigma Aldrich)-coated wells. After $12 \mathrm{~h}$, the cells cultured with the extraction medium as well as $\mathrm{Cu}^{2+}$-added culture medium formed capillary-like structures, whereas no capillary-like structure formed in the blank culture medium or $\mathrm{Zn}^{2+}$-added culture medium (ESI Fig. S3†). The results indicated that $\mathrm{Cu}^{2+}$ had greater angiogenic capacity than $\mathrm{Zn}^{2+}$ and played a leading role in enhancing angiogenic capacity of the BCP scaffold. As the combination of ion dopants and GDF-5 resulted in the highest VEGF secretion level, it was concluded that GDF-5 and $\mathrm{Cu}^{2+}$ might have a synergistic action on enhancing the angiogenic capacity of the BCP scaffold.

According to the results above, we concluded that the incorporation of $\mathrm{Cu} / \mathrm{Zn}$ ions into BCP scaffolds exerted a positive influence not only on osteogenic differentiation, but also on angiogenesis in vitro. Moreover, the addition of GDF-5 further promoted the osteogenic and angiogenic capacities of $\mathrm{Cu} / \mathrm{Zn}$ co-doped BCP scaffold. Although the interaction mechanism of the metallic ions and GDF-5 is unclear, our results do suggest that $\mathrm{Cu} / \mathrm{Zn}$ ions and GDF-5 have a combined effect on osteogenesis and angiogenesis. Therefore, the $\mathrm{Cu} / \mathrm{Zn}$ co-incorporated calcium phosphate scaffolds-derived GDF-5 sustained release system has a promising potential to be used as a superior candidate for bone regeneration. Moreover, the in vivo compatibility of the scaffold will be investigated in our following research.

\section{Conclusion}

In this study, $\mathrm{Cu} / \mathrm{Zn}$ co-incorporated BCP scaffolds combined with GDF-5 sustained release system were successfully prepared. With the increase of adding dopant concentration, the surface micromorphology of the scaffolds changed from smooth grain crystalline to nanoflakes film, accompanying by an increase of the mass ratio of $\beta$-TCP/HA. The results suggested that $\mathrm{Cu} / \mathrm{Zn}$ co-incorporation played an important role in the morphogenesis and phase composition of the BCP scaffold. Additionally, GDF-5-loaded PLGA microspheres were successfully attached onto the BCP scaffold surface and exhibited a sustained release. In vitro cell culture revealed that $\mathrm{Cu} / \mathrm{Zn}$ co-doped BCP scaffold exhibited a combined effect of both angiogenic and osteogenic capacities. Moreover, the sustained release of GDF-5 further enhanced osteogenic and angiogenic capacities of ions-doped BCP scaffold. Although the active mechanism of the metallic ions and GDF-5 on cell behavior remains unclear, the $\mathrm{Cu} / \mathrm{Zn}$ co-incorporated $\mathrm{BCP}$ scaffold-derived GDF-5 sustained release system provides a promising method for fabricating multifunctional scaffolds with improving angiogenic and osteogenic capacities.

\section{Conflicts of interest}

There are no conflicts to declare.

\section{Acknowledgements}

This study was supported by National Natural Science Foundation of China (81171472), Applied Fundamental Program of Science \& Technology Department of Sichuan Province (2016JY0123, 2018JY0100), Technology Innovation Seeding Project of Sichuan Province (2017070), Applied Program of Health and Family Planning Commission of Sichuan Province (17PJ194, 17PJ208, 18PJ476), Key Project of Education Department of Sichuan Province (17ZA0178) and Science \& Technology Project of Nanchong City (NSMC20170310, NSMC20170453).

\section{References}

1 R. Dimitriou, E. Jones, D. Mcgonagle and P. V. Giannoudis, BMC Med., 2011, 9, 1-10.

2 X. Zhang, B. Xu, F. Gao, P. Zheng and W. Liu, J. Mater. Chem. $B, 2017$, 5, 5588-5596.

3 S. Wu, X. Liu, K. W. K. Yeung, C. Liu and X. Yang, Mater. Sci. Eng., $R, 2014$, 80, 1-36.

4 P. Y. Huri, B. A. Ozilgen, D. L. Hutton and W. L. Grayson, Biomed. Mater., 2014, 9, 045003.

5 D. Xiao, T. Guo, F. Yang, G. Feng, F. Shi, J. Li, D. Wang, K. Duan and J. Weng, Ceram. Int., 2017, 43, 1588-1596.

6 G. C. Machado, E. García-Tuñón, R. V. Bell, M. Alini, E. Saiz and M. Peroglio, J. Eur. Ceram. Soc., 2018, 38, 949-961.

7 Y. Li, W. Yang, X. Li, X. Zhang, C. Wang, X. Meng, Y. Pei, X. Fan, P. Lan and C. Wang, ACS Appl. Mater. Interfaces, 2015, 7, 5715-5724.

8 S. Almubarak, H. Nethercott, M. Freeberg, C. Beaudon, A. Jha, W. Jackson, R. Marcucio, T. Miclau, K. Healy and C. Bahney, Bone, 2016, 83, 197-209.

9 B. M. Derby, P. M. Murray, A. Y. Shin, R. A. Bueno, C. L. Mathoulin, T. Ade and M. W. Neumeister, Hand, 2013, 8, 27-40.

10 A. Khojasteh, F. Fahimipour, M. B. Eslaminejad, M. Jafarian, S. Jahangir, F. Bastami, M. Tahriri, A. Karkhaneh and L. Tayebi, Mater. Sci. Eng., C, 2016, 69, 780-788.

11 M. Bouyer, R. Guillot, J. Lavaud, C. Plettinx, C. Olivier, V. Curry, J. Boutonnat, J. L. Coll, F. Peyrin and V. Josserand, Biomaterials, 2016, 104, 168-181.

12 L. Luca, A. L. Rougemont, B. H. Walpoth, R. Gurny and O. Jordan, J. Controlled Release, 2010, 147, 38-44.

13 S. J. Hollister and W. L. Murphy, Tissue Eng., Part B, 2011, 17, 459-474.

14 R. J. Lee, M. L. Springer, W. E. Blancobose, R. Shaw, P. C. Ursell and H. M. Blau, Circulation, 2000, 102, 898-901. 15 C. Han, Y. Ren, Y. Jia, L. Kong, T. Eerdun and L. Wu, Cell Tissue Banking, 2016, 17, 105-115.

16 C. M. Coleman, E. E. Vaughan, D. C. Browe, E. Mooney, L. Howard and F. Barry, Stem Cells Dev., 2013, 22, 1968-1976.

17 E. Degenkolbe, C. Schwarz, C. E. Ott, J. König, K. Schmidtbleek, A. Ellinghaus, T. Schmidt, J. Lienau, F. Plöger and S. Mundlos, Bone, 2014, 73, 111-119.

18 X. Cheng, T. Yang, W. Meng, H. Liu, T. Zhang and R. Shi, Cells Tissues Organs, 2012, 196, 56-67. 
19 H. Kadomatsu, T. Matsuyama, T. Yoshimoto, Y. Negishi, H. Sekiya, M. Yamamoto and Y. Izumi, J. Periodontal Res., 2008, 43, 483-489.

20 K. N. Leknes, J. Yang, M. Qahash, G. Polimeni, C. Susin and U. M. Wikesjö, Clin Oral Implants Res., 2013, 24, 1185-1191.

21 D. H. Kim, K. K. Shin, J. S. Jung, H. H. Chun, S. S. Park, J. K. Lee, H. C. Park and S. Y. Yoon, J. Nanosci. Nanotechnol., 2015, 15, 5520-5523.

22 Z. T. Birgani, E. Fennema, M. J. Gijbels, J. D. Boer, C. A. V. Blitterswijk and P. Habibovic, Acta Biomater., 2016, 36, 267-276.

23 L. Xia, N. Zhang, X. Wang, Y. Zhou, L. Mao, J. Liu, X. Jiang, Z. Zhang, J. Chang and K. Lin, J. Mater. Chem. B, 2016, 4, 3313-3323.

24 F. Ren, R. Xin, X. Ge and Y. Leng, Acta Biomater., 2009, 5, 3141-3149.

25 X. Luo, D. Barbieri, N. Davison, Y. Yan, J. D. de Bruijn and H. Yuan, Acta Biomater., 2014, 10, 477-485.

26 E. S. Thian, T. Konishi, Y. Kawanobe, P. N. Lim, C. Choong, B. Ho and M. Aizawa, J. Mater. Sci.: Mater. Med., 2013, 24, 437-445.

27 C. Gerard and B. Ljbarralet, Biomaterials, 2010, 31, 824-831.

28 S. Zhao, L. Li, H. Wang, Y. Zhang, X. Cheng, N. Zhou, M. N. Rahaman, Z. Liu, W. Huang and C. Zhang, Biomaterials, 2015, 53, 379-391.

29 C. Wu, Y. Zhou, M. Xu, P. Han, L. Chen, J. Chang and Y. Xiao, Biomaterials, 2013, 34, 422-433.

30 X. Ye, C. Zhou, Z. Xiao, Y. Fan, X. Zhu, Y. Sun and X. Zhang, Mater. Lett., 2014, 128, 179-182.

31 F. Shi, W. Zhi, Y. Liu, T. Zhou and J. Weng, Mater. Lett., 2017, 203, 13-16.

32 D. Xiao, Q. Liu, D. Wang, T. Xie, T. Guo, K. Duan and J. Weng, Appl. Surf. Sci., 2014, 309, 112-118.

33 M. Kobayashi, K. Inoue, E. Warabi, T. Minami and T. Kodama, J. Atheroscler. Thromb., 2005, 12, 138-142.

34 G. G. Pekozer, G. T. Kose and V. Hasirci, Microvasc. Res., 2016, 108, 1-9.

35 Y. Kang, S. Kim, M. Fahrenholtz, A. Khademhosseini and Y. Yang, Acta Biomater., 2013, 9, 4906-4915.

36 T. Guo, F. Shi, B. Zhang, J. Li, D. Wang, D. Xiao, R. Duan, W. Zhi, Y. Zheng and J. Weng, Ceram. Int., 2014, 40, 13591-13597.

37 K. Ishikawa, P. Ducheyne and S. Radin, J. Mater. Sci.: Mater. Med., 1993, 4, 165-168.

38 S. Koutsopoulos, J. Biomed. Mater. Res., 2002, 62, 600-612.
39 I. Manjubala and M. Sivakumar, Mater. Chem. Phys., 2001, 71, 272-278.

40 W. Zhang, C. Feng, G. Yang, G. Li, X. Ding, S. Wang, Y. Dou, Z. Zhang, J. Chang and C. Wu, Biomaterials, 2017, 135, 85-95.

41 L. S. Lan, M. B. Polak SJWheeler, A. J. Maki, S. G. Clark, R. D. Jamison and A. J. Wagoner Johnson, Biomaterials, 2010, 31, 3552-3563.

42 C. You, M. H. Lee, H. J. Lee, M. H. Han, T. Y. Kwon, K. H. Kim and D. S. Oh, Ceram. Int., 2017, 43, 3540-3546.

43 Y. Huang, X. Zhang, H. Mao, T. Li, R. Zhao, Y. Yan and X. Pang, RSC Adv., 2015, 5, 17076-17086.

44 Y. Zhang and R. A. Dawe, Chem. Geol., 2000, 163, 129-138.

45 E. J. Elzinga and R. J. Reeder, Geochim. Cosmochim. Acta, 2002, 66, 3943-3954.

46 J. Li, D. Zhai, F. Lv, Q. Yu, H. Ma, J. Yin, Z. Yi, M. Liu, J. Chang and C. Wu, Acta Biomater., 2016, 36, 254-266.

47 X. Wu, G. Meng, S. Wang, F. Wu, W. Huang and Z. Gu, Mater. Sci. Eng., C, 2015, 52, 242-250.

48 A. Park, M. C. V. Hogan, G. S. Kesturu, R. James, G. Balian and A. B. Chhabra, Tissue Eng., Part A, 2010, 16, 2941-2951.

49 S. Choi and W. L. Murphy, J. Mater. Chem., 2012, 22, 2528825295.

50 X. Shen, P. Ma, Y. Hu, G. Xu, J. Zhou and K. Cai, Colloids Surf., B, 2015, 127, 221-232.

51 K. Sena, D. R. Sumner and A. S. Virdi, Connect. Tissue Res., 2007, 48, 324-331.

52 K. Felix Peter, W. Christoph, H. Elisabeth, A. N. Bilal and W. Wilfried, Int J Periodontics Restorative Dent., 2012, 32, 285-293.

53 H. Cheng, L. Mao, X. Xu, Y. Zeng, D. Lan, H. Hu, X. Wu, H. You, X. Yang and R. Li, Biomater. Sci., 2015, 3, 665-680.

54 J. Bejarano, R. Detsch, A. R. Boccaccini and H. Palza, J. Biomed. Mater. Res., Part A, 2016, 105, 746-756.

55 A. Hoppe, N. S. Güldal and A. R. Boccaccini, Biomaterials, 2011, 32, 2757-2774.

56 S. Almubarak, H. Nethercott, M. Freeberg, C. Beaudon, A. Jha, W. Jackson, R. Marcucio, T. Miclau, K. Healy and C. Bahney, Bone, 2015, 83, 197-209.

57 Q. Zeng, X. Li, G. Beck, G. Balian and F. H. Shen, Bone, 2007, 40, 374-381.

58 K. Kleinschmidt, M. Wagner-Ecker, B. Bartek, J. Holschbach and W. Richter, J. Bone Jt. Surg., Am. Vol., 2014, 96, 16991707.

59 X. Zhang, J. Li, X. Wang, Y. Wang, R. Hang, X. Huang, B. Tang and P. K. Chu, Mater. Sci. Eng., C, 2018, 82, 110-120. 